\title{
Usos das TIC na escola: um caso numa escola pública do Brasil
}

\author{
Uses of ICT in school: A case in a public school of Brazil
}

\author{
Ananda Heloisa de Mello*, Lia Raquel de Oliveira** \\ *Universidade Estadual do Rio Grande do Sul, Brasil. **Universidade do Minho, Portugal.
}

\begin{abstract}
Resumo
As Tecnologias da Informação e Comunicação (TIC) estão presentes nas escolas e invadem o nosso quotidiano. Os alunos usam-nas. Assim, pretendemos saber quais os usos que estão sendo feitos das TIC, como ferramentas pedagógicas, em uma turma de alfabetização de uma escola pública da esfera municipal, no Brasil. Para tanto, propomos um estudo de caso, tendo como referências Yin, 1994; Bogdan e Biklen, 1994, Coutinho (2013), entre outros, visando ter uma descrição detalhada de todos os processos envolvidos no processo de alfabetização de crianças, no Brasil. Pretende-se com este estudo incentivar a utilização das TIC em sala de aula, por parte dos professores e alunos, e fazê-los ver a importancia da utilização das TIC na educação. Palabras clave: Tecnologias da Informação e Comunicação na Escola; usos das TIC na educação; alfabetização
\end{abstract}

\begin{abstract}
Information and Communication Technologies (ICTs) are present in schools and break into our daily lives. Students use them. So we want to know what are the uses being made of ICT as teaching tools in a 1st grade class in a downtown brasilian public school. We propose a case study regarding a detailed description of all the processes involved.

Keywords Information and Communication Technologies in school; using ICT in education; literacy
\end{abstract}

\section{Problema e fundamentação}

As TIC integram o quotidiano das crianças no Brasil, com diferentes intensidades: os que possuem equipamentos (computador, tablet, smartphone) e acesso a Internet (na casa e na rua); os que possuem estes bens em casa de forma partilhada; os que não possuem mas usam na rua, nas Lan Houses; e as que não conhecem sequer. Esta é a diversidade de usos observável e que, seguramente, terá outras variedades.

A investigação em curso que relatamos nasce do recorrente relato de professores e gestores sobre o uso deficiente das salas de informáticas e sobre as tecnologias em geral, na escola pública: computadores fechados em armários, avariados, etc. Mesmo assim, ainda existem muitas escolas de cidades grandes sem acesso à Internet e sem ao menos uma sala equipada de computadores.
Porém, várias políticas públicas foram implementadas e algumas escolas usam essas tecnologias.

Muitos professores tem refletido sobre a tecnologia e sua aplicação em sala de aula. Porém, muitos professores ainda não sabem como trabalhar com elas porque não tiveram formação para o efeito. Verifica-se um grande desfasamento nas formações destes profissionais, que acabam não utilizando. Sabemos que as tecnologias estão aí para serem usadas e é preciso desmistificar as barreiras existentes quanto ao seu uso na educação.

A sociedade globalizada exige ao sistema educativo que prepare os jovens para integrar a Economia do Conhecimento que estamos vivendo. Essa sociedade, configurada no mercado, exige profissionais que tenham conhecimento e hábitos de trabalho colaborativo e que se sintam à vontade com as TIC. Escolas e professores defrontam-se com esse desafio. Como preparar, desde logo as crianças, para esse perfil? Sem descurar a aprendizagem das matérias curriculares nem os objetivos de socialização e de desenvolvimento pessoal?

Este estudo tenciona conhecer de que maneira os professores de uma turma da rede pública de ensino estão trabalhando com as tecnologias em aula e de que maneira se utilizam disso na alfabetização das crianças.

Trata-se, também, de perceber se as TIC são usadas em substituição de práticas antigas e desadequadas aos nossos dias, ou seja, se se trata "de usar a tecnologia pela tecnologia [ou] porque esta tecnologia (...) permite introduzir na sala de aula atividades que sem ela não seriam possíveis. " (Oliveira et al, 2013).

\section{Objeto de estudo, questões e objetivos}

O objeto de estudo em causa são os usos (Le Coadic, 1997; Boenisch, 2008; Perriault, 1989) das TIC que alunos e professoras delas fazem em situação escolar. Debruça-se sobre as atividades levadas a cabo, para efeitos académicos, quer por alunos quer por professoras, no contexto da alfabetização de crianças. Tenta-se dar resposta à seguinte questão de investigação: - Como a tecnologia está sendo usada na escola pública brasileira, em uma turma de alfabetização?

Para responder à questão, elaboramos os seguintes objetivos:

- construir um referencial teórico que permita analisar os usos das TIC;

- caracterizar o estabelecimento de ensino;

- caracterizar os usos nesse contexto por alunos e professoreas (equipamentos e tecnologias usadas, tipo de atividades realizadas, etc) 
- identificar as formações frequentadas pelos professores/as em TIC e procurar uma eventual relação com as práticas letivas;

- elencar os desafios colocados às professoras pelo uso das TIC e compreender se alguma perspetiva educacional está embasando suas opiniões;

- refletir sobre o uso das TIC nas escolas e discutir sua relevância;

- divulgar os resultados obtidos para motivar sua discussão.

\section{Metodologia}

\section{Tipo de estudo}

Trata-se de um estudo de caso (Yin, 1994; Bogdan e Biklen, 1994). Existem diversas visões teóricas em relação ao estudo de caso. Segundo Coutinho (2013), baseada em Yin (1994), o estudo de caso tem como objetivos explorar, descrever ou explicar a unicidade em estudo. Apesar de diferentes correntes de estudiosos na área, Gomez, Flores e Jimenez (1996 apud Coutinho e Chaves, 2002), buscam sintetizar tais concepções trazendo como objetivos do estudo de caso explorar, descrever, explicar, avaliar e/ou transformar.

Coutinho e Chaves (idem), citam vários autores que contribuem para a consistência da metodologia investigativa qualitativa e apresentam, inicialmente, os tipos definidos por Stake (1998) para os estudos de caso, como uma classificação elementar:

- intrínseco: caso específico, de particular interesse, que por si só já justifica a investigação;

- instrumental: onde os resultados de um caso extrapolam os limites de interesse do caso em si, cujo detalhamento permite reforçar ou complementar uma teoria.

- coletivo: é a consecução de vários casos instrumentais passíveis de comparação, onde o resultado das investigações pode ser cotejado, possibilitando refinamento e aprofundamento no tema pesquisado.

\section{Contexto da investigação, participantes e questões éticas}

O estudo desenvolve-se numa escola da rede municipal de ensino do muncípio de Novo Hamburgo- RS, município com cerca de 245000 habitantes. A escola possui cerca de 600 alunos, 49 professores, 8 funcionários e sala de informática, com 17 computadores e acesso a internet de banda larga.

A turma da pesquisa é do primeiro ano do ensino fundamental: 29 alunos e 2 professoras. A pesquisa iniciou em 2014, quando estes alunos já estavam em fase adiantada de aprendizagem, último trimestre letivo.

Do ponto de vista ético, as atividades relacionadas com a investigação não interferem com o habitual desenvolvimento curricular e foi pedida autorização à gestão da escola, para que pudesse haver interação com a turma e observação da rotina de ensino.

\section{Procedimentos, técnicas e instrumentos de recolha de dados}

A investigação está organizada em três momentos, suportados em duas técnicas: A) observação B) inquérito por questionário (de caracterização e de opinião); c) inquérito por entrevista.

As técnicas e instrumentos de recolha de dados utlizados são os adequados a cada momento, sendo a observação não participante e participante uma constante e a administração do questionário feita de forma personalizada, com auxílio das professoras (visto muitas crianças ainda não estarem ainda alfabetizadas). Em síntese, os instrumentos utilizados são: a análise documental (documentos da escola e das professoras); a observação participante e não participante, de acordo com a situação, com registos em diário; o inquérito por questionário (de caracterização e de opinião) e por entrevista (semi-estruturada, coletiva e/ou individual). É função da entrevista confirmar/confrontar/clarificar/apurar/afinar dúvidas resutantes da análise dos dados obtidos com o questionário.

Como tratamento dos dados serão analisados os registos em diário elaborados durante as observações, os dados obtidos com o questionário e com a entrevista. Teremos análise de conteúdo (Bardin, 1997) e estatística descritiva quando se justificar.

Descriminam-se os momentos e as respetivas tarefas (T).

A) Construção do referencial teórico e dos instrumentos

T1 - sistematização da literatura e elaboração do quadro teórico;

T2 - elaboração dos instrumentos de recolha de dados (questionário de caracterização e de opinião, para alunos/as e professoras) e respetiva validação por elementos do público-alvo;

T3 - caracterização da escola (entrevista com responsável e análise de documentos do estabelecimento).

B) Recolha de dados

T1 - administração de questionários;

T2 - realização de entrevistas

C) Tratamento, interpretação e discussão dos dados

T1 - organização dos dados;

T2 - tratamento de dados e interpretação;

T3 - cruzamento dos resultados obtidos com os instrumentos;

T4 -conclusões e finalização da redacção final do estudo.

\section{Resultados esperados}

Esperamos caracterizar esse estabelecimento de ensino e os usos das TIC percebidos e que os alunos e professoras envolvidas se sintam mais conscientes da necessidade de utilizar as TIC em aula.

\section{Referências}

Bardin, L. (1994). Análise de Conteúdo. Lisboa: Edições 70.

Bogdan, R. \& Biklen, S. (1994). Investigação Qualitativa em Educação. Uma introdução à teoria e aos métodos. Porto: Porto Editora. 
Boenisch, G. (2008). Jacques Perriault, La logique de l'usage. Essai sur les machines à communiquer. Questions de communication, 15, 2009, pp. 503-504.

Coutinho, C. P., \& Chaves, J. H. (2002). O Estudo de caso na investigação em Tecnologia Educativa em Portugal. (C. -U. Minho, Ed.) Revista Portuguesa de Educação, 15(1), 221-243.

Coutinho, C. M. (2013). Metodologia de Investigação em Ciências Sociais e Humanas: teoria e prática. Coimbra, Portugal: Almedina

Le Coadic, Y. (1997) Usages et Usagers de l'Information. Paris: Nathan Université.
Oliveira, L. R.; Martins, L.; Capitão, M.; Costa, M.; Barbosa, H.; Cardoso, E. \& Santos, B. (2013). Data is a Built Thing: (de)constructing the curriculum through Wikipedia writing. Procedings of EduLearn 2013, Barcelona. Pp. 0120-0125.

Perriault, J. (1989). La logique de l'usage. Essai sur les machines à communiquer. Paris: L'Harmattan.

Stake, R. (1998). Investigación com estudios de casos. Madrid: Morata.

Yin, R. (1994). Case Study Research: design and methods ( $\left.2^{\text {nd }} E d\right)$. Thousand Oaks, CA: Sage Publications. 